\title{
One-step Growth of Well Aligned K-doped ZnO Nanotapers Using a Facile Electrochemical Route: Photocatalyst Application
}

\author{
Yang Ren", Sen Han, Chen Liu, Yimin Feng, Kaoxue Li, Mingjun Song, \\ College of Chemistry \& Chemical and Environmental Engineering, Weifang University, Shandong \\ 261061, China \\ "E-mail: renyangwf@163.com
}

doi: $10.20964 / 2019.07 .56$

Received: 6 March 2019 / Accepted: 2 May 2019 / Published: 10 June 2019

\begin{abstract}
Large-scale oriented $\mathrm{K}$-doped $\mathrm{ZnO}$ nanotapers were successfully grown on fluorine-doped tin oxide glass substrate using a facile electrochemical route. FESEM, TEM and HRTEM results indicate wellaligned taper-like single-crystalline $\mathrm{ZnO}$ hexagonal structure were achieved evidenced by a strong preferential growth along [0001] c-axis direction. Room temperature photoluminescence and Raman spectra results suggest the $\mathrm{K}$ doping introduced defect local electronic configuration. The $\mathrm{K}$-doped $\mathrm{ZnO}$ nanotaper arrays used as photocatalysts present good photocatalytic performance to the degradation of 1,1,1-trichloro-2,2-bis (4-chlorophenyl) ethane (DDT) under simulated sunlight attribute to the $\mathrm{K}$ doping. The results reveal that taper-like $\mathrm{K}$-doped $\mathrm{ZnO}$ nanostructures have significant and high photocatalytic actively and suitable alternative to other photocatalytic materials for environmental and water detoxification.
\end{abstract}

Keywords: K-doped $\mathrm{ZnO}$ nanotapers; Photocatalytic activities; Electrochemical method; Organochlorine pollutants

\section{$\underline{\text { FULL TEXT }}$}

(C) 2019 The Authors. Published by ESG (www.electrochemsci.org). This article is an open access article distributed under the terms and conditions of the Creative Commons Attribution license (http://creativecommons.org/licenses/by/4.0/). 